Transport and Communications Science Journal

\title{
EXPERIMENTAL STUDY ON FLEXURAL AND SHEAR BEHAVIOUR OF SANDWICH PANELS USING GLASS TEXTILE REINFORCED CONCRETE AND AUTOCLAVED AERATED CONCRETE
}

\author{
Bui Thi Thanh Mai ${ }^{1}$, Nguyen Huy Cuong1, Ngo Dang Quang ${ }^{1}$, Dinh Huu Tai ${ }^{1}$ \\ ${ }^{1}$ University of Transport and Communications, No 3 Cau Giay Street, Hanoi, Vietnam.
}

\author{
ARTICLE INFO \\ TYPE: Research Article \\ Received: 13/11/2019 \\ Revised: $12 / 01 / 2020$ \\ Accepted: 13/01/2020 \\ Published online: 31/01/2020 \\ https://doi.org/10.25073/tcsj.71.1.3 \\ * Corresponding author \\ Email: bttmai@utc.edu.vn ; Tel: 0983525001
}

\begin{abstract}
Textile-reinforced concrete (TRC) is a new composite material made of highstrength textiles embedded within fine grained concrete (FGC). The application of TRC leads to the design of thin and slender structures or for repairing and strengthening of existing structural members. Autoclaved aerated concrete (AAC) is an ultra-lightweight concrete, which can be combined with high strength TRC to form some kinds of precast curtain panels in construction. The concept of the TRC-AAC panel is based on the theory of sandwich construction with strong and stiff skins, like TRC layers, bonded to a lightweight AAC core. The resulting hybrid TRC-AAC panel can be used as structural or non-structural member for the housing construction. In this paper, the flexural and shear performance of hybrid TRCAAC sandwich panels is presented by means of experimental results. The sandwich panels use three layers of different materials: TRC for the tensile layer, AAC for the core material and FGC for the compressive layer. Three different types of glass textile were used as reinforcements in the TRC layers.
\end{abstract}

Keywords: Textile reinforced concrete, TRC, AAC, sandwich, flexure, shear.

(C) 2020 University of Transport and Communications

\section{INTRODUCTION}

Recently, carbon and glass textiles have emerged as a promising alternative material to conventional steel reinforcement in concrete structures, which results in increased durability 
and reliability of civil engineering construction. These textiles are extremely strong in tension, non-corrosive, and can be used to eliminate the corrosion problem invariably encountered with conventional reinforcing steel. High-strength textile materials are widely used in various fields of construction, including the construction of unique buildings and structures, road construction, hydraulic engineering, and others. Textile reinforced concrete (TRC) is a combination of high performance fine grained concrete and high tensile strength textile reinforcement, which can be used in form of millimeter thin layers [1].

Due to the suitability of the properties for thin layers, TRC has been successfully applied for strengthening existing buildings as well as fabricating new structural elements [1-3]. A wide range of prefabricated products using TRC exists, including exterior cladding panels, parapet walls, and sandwich panel v.v. Research on TRC-based sandwich panels has also been conducted by Hegger [4], Schneider [5], Cuypers [6], Nguyen Viet Anh [7] and Vu Van Hiep [8] v.v. These panels comprise TRC layers with difference core materials, such as plastic foams or lightweight concrete. Fundamental work on sandwich panels with thin-walled TRC facings has been done by Hegger [4]. In this work, Hegger tested different configurations of TRC sandwich panels, which comprised a $150-\mathrm{mm}$ thick core layer made of polyurethane foam and two ankali resistance-glass TRC skin layers. Hegger reported that the loadbearing and deformation capacity of the specimens were primarily dependent on the core stiffness. Schneider [5] carried out the three- and four-point bending tests with sandwich specimens consisted of $8 \mathrm{~mm}$ thick TRC facings with an $80-\mathrm{mm}$ thick insulating core. Schneider used different textile materials (AR-glass and carbon) and incorporated different core materials (PU of varying densities or aerated concrete). Nguyen Viet Anh [6] developed a new type of sandwich beams using TRC skins and Expanded Polystyrene Concrete in the core. The test results indicated that the bond resistance between the layers of sandwich beams is ensured without any shear connector device. Vu Van Hiep [7] also proposed the hybrid structure consisting of three layers with different materials: TRC for the tension skin, lightweight concrete as a core material and fine grained concrete for the compression skin.

Autoclaved aerated concrete (AAC) is an ultra-lightweight concrete with a distinct cellular structure, with a dry bulk density ranging from 400 to $800 \mathrm{~kg} / \mathrm{m}^{3}$ and a compressive strength ranging from 3 to $7 \mathrm{MPa}$. Entrained air bubbles are the main cause for its enhanced physical properties. The low density and porous structure give the AAC excellent thermal and sound insulation properties. High precision block units of unreinforced AAC can be used in non-load bearing walls. Currently AAC block is reinforced with a conventional steel, in the form of long-span panels for roof and floor decks, exterior walls, and lintels [8-10]. However, AAC material provides little protection to steel reinforcement against corrosion, which can cause destruction of the structure by reducing the effective cross-sectional area of the bars and consequently increasing the stresses in the structure. In addition to improving strength and ductility, the reinforcement of the AAC panels with TRC skins is also expected to enhance durability performance leading to reduced maintenance costs of structures. Moreover, as textile is noncorrosive material, there would not be any corrosion problems for the hybrid panels as in the case of the steel reinforced AAC.

The structural characterization of hybrid glass TRC - AAC sandwich panels for building construction is presented in this article. The proposed hybrid panel is a sandwich structure consisting of three layers with different materials: TRC for the tension skin, AAC as a core material and fine grained concrete (FGC) for the compression skin. As there are no previous research data available on the structural behavior of TRC-AAC sandwich panels, three sets of specimens were carried out with three different types of glass textile reinforcements. In order to 
determine the flexural and shear capacity of the sandwich panels, four-point bending tests were carried out on beam-type specimens. The test results, including load - deflection behavior, crack patterns, ultimate capacities, and modes of failure, will be introduced in this article.

\section{SPECIMENS AND TEST DESCRIPTION}

\subsection{Test specimens}

In this experiment, 18 TRC-AAC sandwich panels in three sets were tested. All the panels have the same dimension of $200 \times 150 \times 600 \mathrm{~mm}$ (Figure 1). In order to investigate both the flexural and shear behavior of the sandwich panels, four-point bending tests were carried out on beam-type specimens, with $150 \mathrm{~mm}$ shear span (i.e. shear span to depth ratio equals 1.0). The TRC layer at the bottom and FGC layer at the top have the same thickness as $15 \mathrm{~mm}$. The AAC core layer has $120 \mathrm{~mm}$ thickness, which was cut from precast AAC panel with the original dimension of $600 \times 120 \times 1200 \mathrm{~mm}$. The TRC and FGC layers were bonded to the top and bottom surface of AAC block by plastering method.
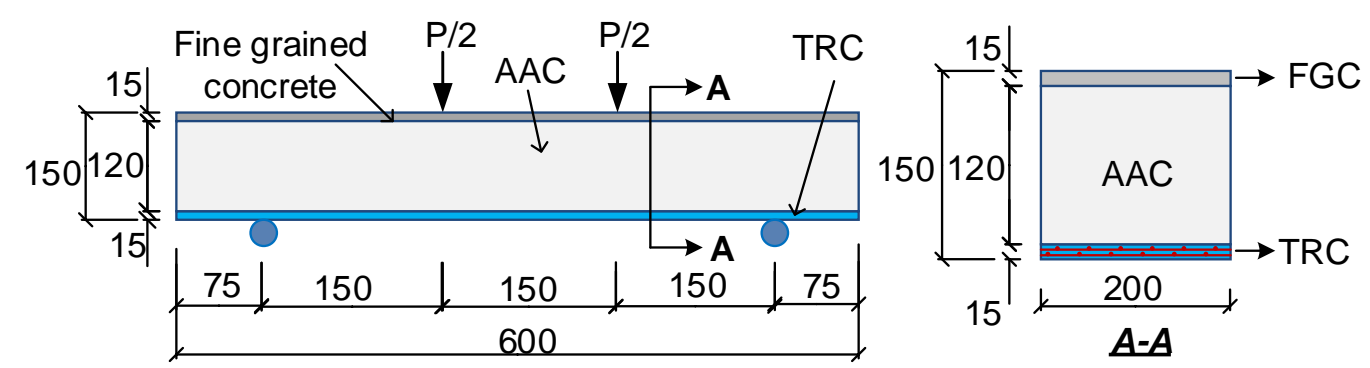

Figure 1. Dimensions of test specimen.

Three sets of sandwich panels were tested, corresponding to three types of glass textile, namely: type A (GRID Q20/20-ASS-13 applied in 10 panels), type B (SITgrid200KE applied in 4 panels) and type $C$ (Fiber glass 100/100 applied in 4 panels). In each set, the TRC skin has different number of glass textile layers, vary from $1 \div 5$ layers in set $\mathrm{A}, 1 \div 2$ layer in 2 nd set and 3rd set. There are two replicates of each parameter were tested. Specimens were named following the notation SWxy-z, where $x=$ type of glass fiber, $y=$ number of textile layer, and $z=$ specimen number. For example, the label SWB2-1 represents 1st sandwich specimen with 2 layers of glass textile type B. The details information for each panel is mentioned in Table 2.

\subsection{Material properties}

The FGC with a maximum grain size of $0.6 \mathrm{~mm}$ was specifically designed for application with glass textile. The high performance plasticizer and fly ash were added to achieve a very good flowing capability of the concrete in order to ensure a proper penetration of the small gaps of the fabrics. According to the TCVN 6016:2011, the obtained average flexural strength and average compressive strength at 28 days were equal to $6.4 \mathrm{MPa}$ and $43.6 \mathrm{MPa}$, respectively. AAC panels with dry density of $750 \mathrm{~kg} / \mathrm{m} 3$ was manufactured and provided by Labaco-building Co.ltd. The average compressive strength of AAC cylinder specimens was 3.5 MPa. 
Transport and Communications Science Journal, Vol. 71, Issue 1 (01/2020), 18-26

Table 1. The geometrical and mechanical characteristics of three types of glass textiles.

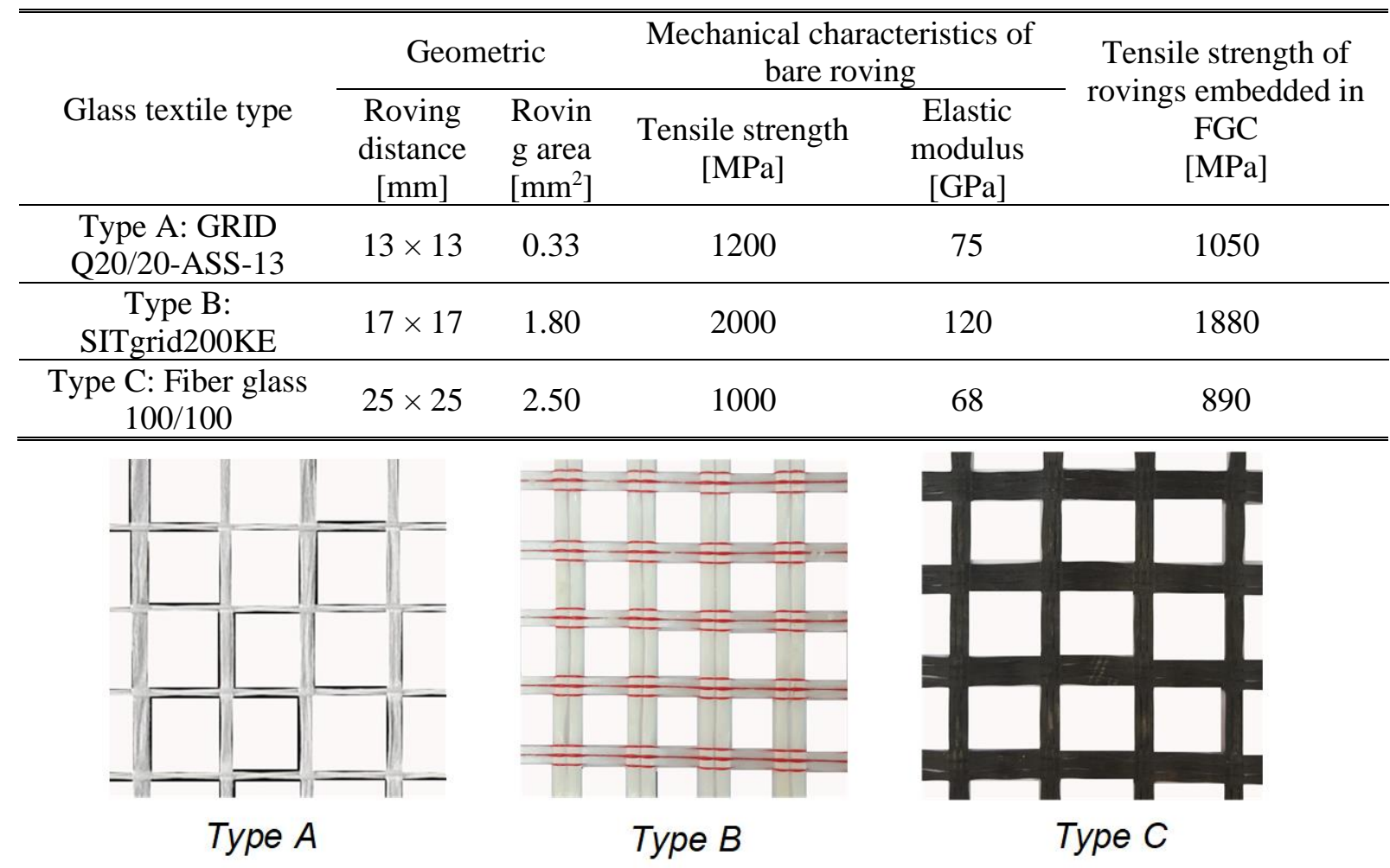

Figure 2. Three type of glass textiles.

Table 1 summaries the geometrical and mechanical characteristics of three different types of glass textiles. The tensile strength and elastic modulus of the rovings were measured by means of tensile tests on bare roving coupons (i.e. not impregnated by the fine grained concrete). Several researchers reported that with the composite material TRC, the tensile strength of the filaments cannot be fully exploited [1]. The main reason for this is the decreasing bond performance from the outer filaments towards the inner core of the roving. To obtain the mechanical properties of the textile embedded in concrete, six coupons of the TRC plates were prepared for each type of glass rovings. These specimens were tested in uniaxial tensile test. The average tensile strength of glass rovings embedded in FGC is also reported in Table 1.

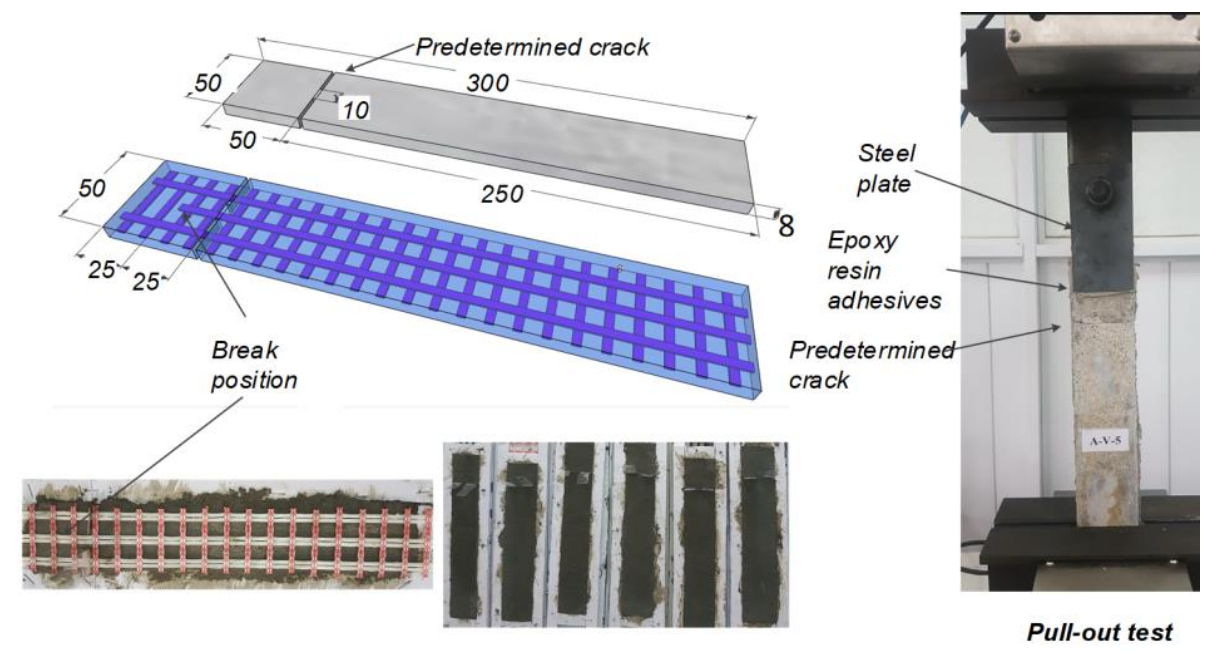

Figure 3. Specimen for pull-out test. 
For preparing this experiment, a serie of basic tests were carried out to obtain the mechanical properties of TRC layers, including: bond behavior of glass textiles and FGC; interfacial bond strength between FGC and AAC. The bond behavior between textile and FGC was studied using the pull-out tests (Figure 3), according to recommendations of Zulassung Z-31.10-182 (Germany). The average bonding strength between glass rovings type $B$ and type $C$ was $28.2 \mathrm{~N} / \mathrm{mm}$ and $18.6 \mathrm{~N} / \mathrm{mm}$. The interfacial bond strength is commonly studied through a direct shear test in which a FGC cylinder part bonded to an AAC part is subjected to direct shear force (Figure 4). The average bonding strength between FGC and $\mathrm{AAC}$ was found approximately 1.22 $\mathrm{MPa}$.

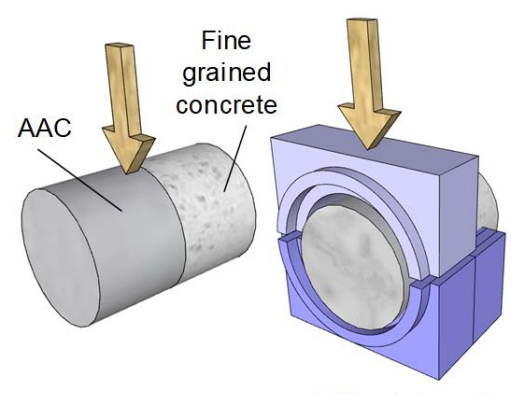

a) Direct shear test

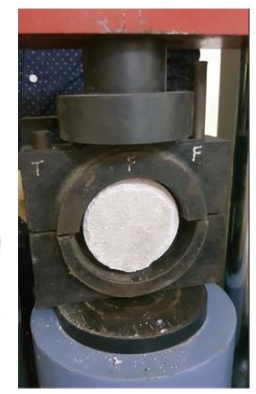

Figure 4. Direct shear test.

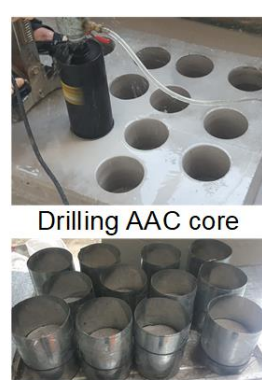

b) Casting fine grained concrete
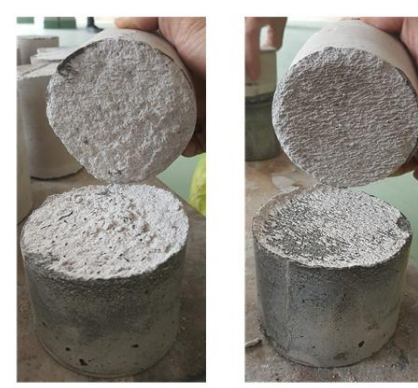

c) Failure mode: debonding

\subsection{Test setup and instrumentation}

For fabricating specimen, a layer of $15 \mathrm{~mm}$ thick FGC was firstly applied on the bottom surface of the AAC core block. After that, another layer of FGC was plastered to the top surface of AAC core. The glass textile was then pressed slightly into the FGC until the FGC protruded out of the perforations between the rovings. The second FGC layer was then applied to completely cover the textile fabric and the procedure was repeated for each layer of TRC (Figure 5-a,b).

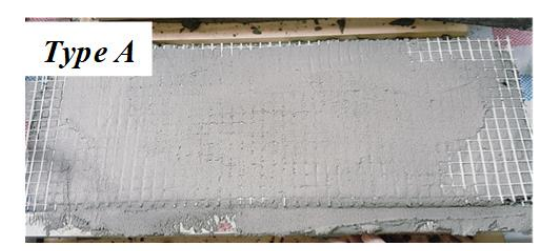

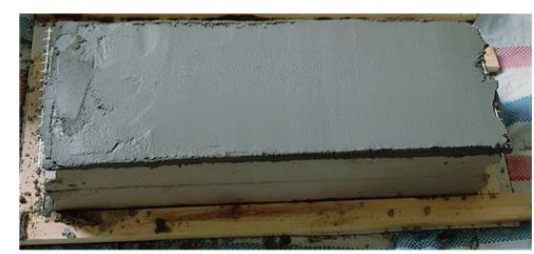

b) Finishing test specimen a) Plastering TRC with glass textiles
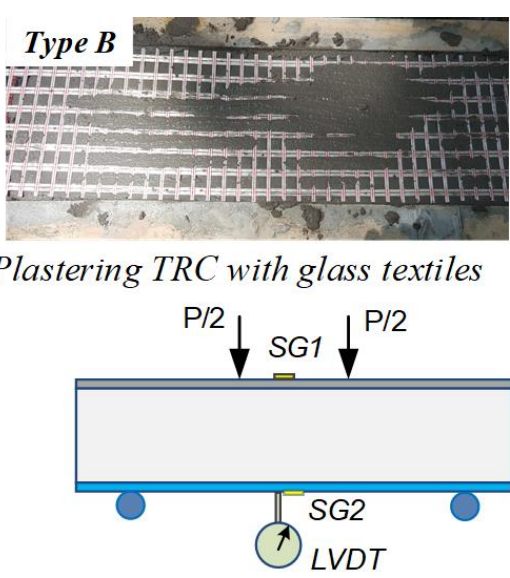

c) Strain-gages and LVDT
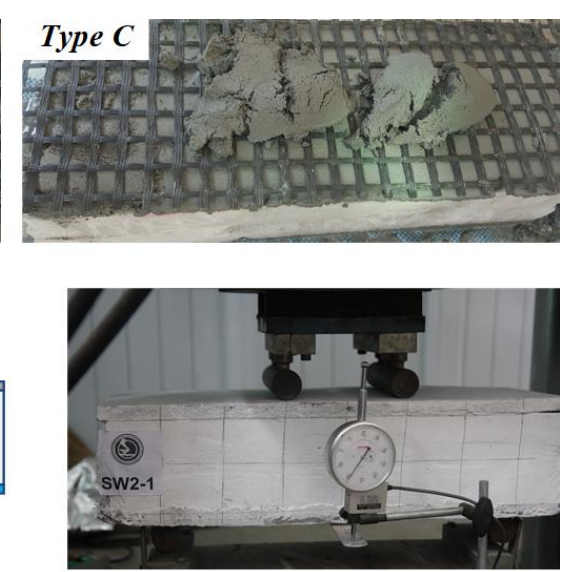

d) Test setup instrumentation

Figure 5. Fabricating specimens and test setup.

All test specimens were air cured in indoor conditions for 28 days. The panels were tested with four-point bending, using displacement controlled method, with loading rate of 1 $\mathrm{mm} / \mathrm{min}$. Schematic view and a view of the test setup are shown in Figure 5-c, d. A LVDT 
was installed on the bottom surface of the panels to measure its deflection during the test. Moreover, strain gages were used to record concrete strains at top and bottom surfaces. All the tests were conducted in the Structural Engineering Laboratory at University of Transport and Communications, Vietnam.

\section{EXPERIMENTAL RESULTS}

The load versus deflection curves are presented as shown in Figure 6 and Figure 8 for all three sets. Table 2 shows a summary of the ultimate load of all test specimens. In addition, failure modes and crack patterns of sandwich panels are illustrated in Figure 7 and 9. Figure 6-a shows the load deflection behavior of the five sandwich panels in 1st set, using $1 \div 5$ layers of glass textile type A. All panels show the similar load bearing behavior. The load deflection curves indicate an almost linear elastic behaviour, up to the point of first flexural crack (Figure 7-a) appears, at a load level of $18 \div 20 \mathrm{kN}$. Stiffness of the panels decreased after the first cracks, resulting in larger deflection. With these panels using $1 \div 3$ layers, due to very small reinforcement ratios, the remaining loads were much small than the cracking load. Due to the bond between textile roving and FGC, tensile stress was developed in the concrete, until the tensile strength of the FRC is reached once more. With an increasing of the tension force, additional cracks occurred, resulting the continuous multiple cracks (Figure 7-a). By a load increase, the rovings are strained up to their tensile strength. In this stage, the crack pattern was stabilized, no further cracks occur, but the biggest crack expanded larger. Then, the textile reinforcement was continuously broken, resulting the flexural failure mode.

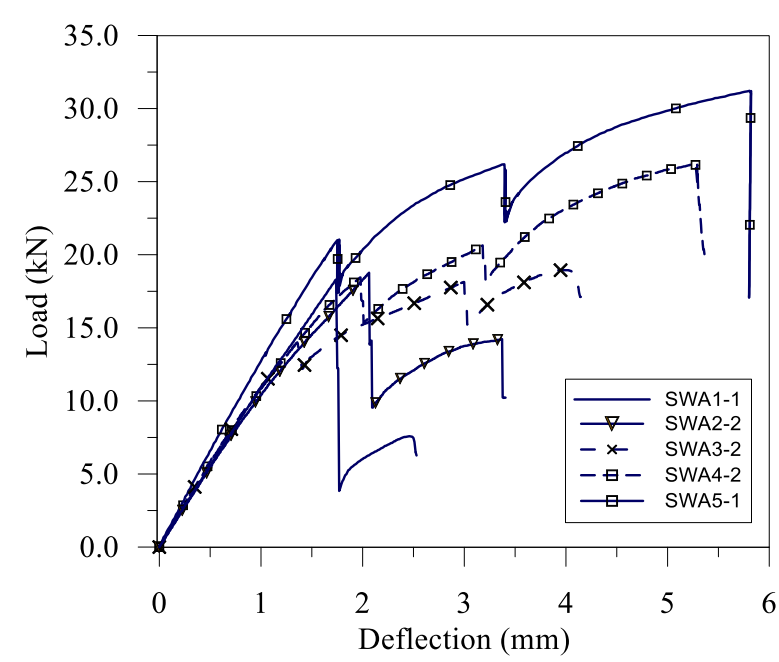

a) SWA beams in Set 1

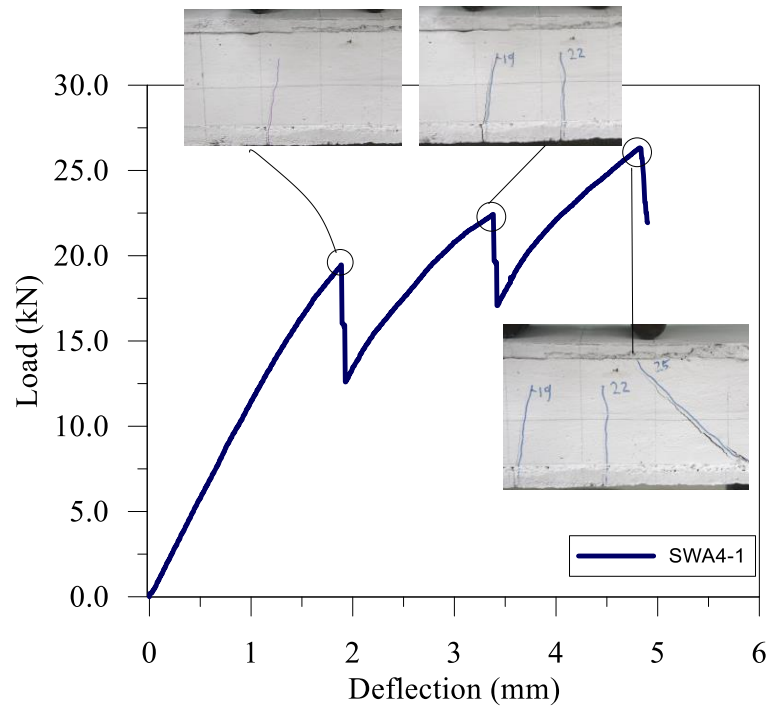

b) SWA4-1 sandwich beam

Figure 6. Load-deflection of tested sandwich panels in Set 1.

Table 2. Ultimate load of sandwich specimens.

\begin{tabular}{|c|c|c|c|c|c|c|c|c|}
\hline \multirow[b]{2}{*}{ Set } & \multirow[b]{2}{*}{ Panel } & \multicolumn{3}{|c|}{ Textile reinforcement } & \multicolumn{3}{|c|}{ Load (kN) } & \multirow[b]{2}{*}{ Failure mode } \\
\hline & & $\begin{array}{c}\mathbf{N}^{\mathbf{o}} \\
\text { layers }\end{array}$ & $\begin{array}{c}\text { Total } \\
\text { area } \\
\left(\mathbf{m m}^{2}\right)\end{array}$ & $\begin{array}{c}\text { Ratio } \\
(\%)\end{array}$ & $\begin{array}{c}\text { Crack } \\
\text {-ing }\end{array}$ & $\begin{array}{l}\text { Load at } \\
\text { failure }\end{array}$ & $\begin{array}{l}\text { Ultim } \\
\text {-ate }\end{array}$ & \\
\hline \multirow{2}{*}{$\begin{array}{l}\text { Set 1: } \\
\text { SWA }\end{array}$} & SWA1-1 & \multirow{2}{*}{1} & \multirow{2}{*}{4.67} & \multirow{2}{*}{0.016} & 18.30 & 7.58 & 18.30 & \multirow{2}{*}{$\begin{array}{l}\text { Tensile break of } \\
\text { textile/ Flexure }\end{array}$} \\
\hline & SWA1-2 & & & & 17.84 & 7.15 & 17.84 & \\
\hline
\end{tabular}


Transport and Communications Science Journal, Vol. 71, Issue 1 (01/2020), 18-26

\begin{tabular}{|c|c|c|c|c|c|c|c|c|}
\hline & SWA2-1 & \multirow{2}{*}{2} & \multirow{2}{*}{9.33} & \multirow{2}{*}{0.033} & 19.70 & 1.98 & 19.70 & \multirow[t]{4}{*}{ failure } \\
\hline & SWA2-2 & & & & 18.77 & 14.22 & 18.77 & \\
\hline & SWA3-1 & \multirow{2}{*}{3} & \multirow{2}{*}{14} & \multirow{2}{*}{0.049} & 19.65 & 19.03 & 19.65 & \\
\hline & SWA3-2 & & & & 18.13 & 18.95 & 18.95 & \\
\hline & SWA4-1 & \multirow{2}{*}{4} & \multirow{2}{*}{18.67} & \multirow{2}{*}{0.065} & 19.45 & 26.33 & 26.33 & \multirow{4}{*}{$\begin{array}{c}\text { Diagonal cracks } \\
\text { Shear failure }\end{array}$} \\
\hline & SWA4-2 & & & & 18.44 & 26.22 & 26.22 & \\
\hline & SWA5-1 & \multirow{2}{*}{5} & \multirow{2}{*}{23.35} & \multirow{2}{*}{0.08} & 19.54 & 31.21 & 31.21 & \\
\hline & SWA5-2 & & & & 18.69 & 27.48 & 27.48 & \\
\hline \multirow{4}{*}{$\begin{array}{l}\text { Set 2: } \\
\text { SWB }\end{array}$} & SWB1-1 & \multirow{2}{*}{1} & \multirow{2}{*}{19.8} & \multirow{2}{*}{0.068} & 19.84 & 26.02 & 26.02 & \multirow{4}{*}{$\begin{array}{c}\text { Diagonal cracks } \\
\text { Shear failure }\end{array}$} \\
\hline & SWB1-2 & & & & 18.25 & 25.68 & 25.68 & \\
\hline & SWB2-1 & \multirow{2}{*}{2} & \multirow{2}{*}{39.6} & \multirow{2}{*}{0.137} & 18.69 & 27.38 & 27.38 & \\
\hline & SWB2-2 & & & & 21.48 & 30.79 & 30.79 & \\
\hline \multirow{4}{*}{$\begin{array}{l}\text { Set 3: } \\
\text { SWC }\end{array}$} & SWC1-1 & \multirow{2}{*}{1} & \multirow{2}{*}{20} & \multirow{2}{*}{0.069} & 16.92 & 20.47 & 20.47 & \multirow{2}{*}{$\begin{array}{l}\text { Textiles break / } \\
\text { Flexure failure }\end{array}$} \\
\hline & SWC1-2 & & & & 17.82 & 22.52 & 22.52 & \\
\hline & SWC2-1 & \multirow{2}{*}{2} & \multirow{2}{*}{40} & \multirow{2}{*}{0.138} & 21.83 & 28.01 & 28.01 & \multirow{2}{*}{$\begin{array}{c}\text { Diagonal cracks } \\
\text { Shear failure }\end{array}$} \\
\hline & SWC2-2 & & & & 20.23 & 30.07 & 30.07 & \\
\hline
\end{tabular}

All four sandwich panels with 4 and 5 layers had a similar failure process with diagonal shear cracking initiated in the shear span regions. The typical load - deflection behavior was plotted in Figure 6-b. The diagonal cracks then increased dramatically and propagated toward the top area and develop across the spans with increasing load. The shape and pattern of cracking are also shown in Fig. 7-b.

Figure 6. Load-mid span deflection curves for sandwich panels in $1^{\text {st }}$ set.

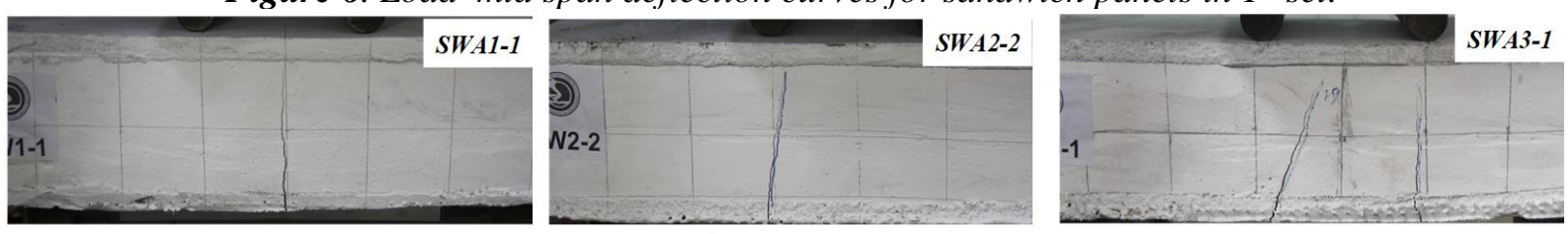

a) Flexural cracks in $1^{\text {st }}$ set with 1, 2, 3 layers of textile type $A$
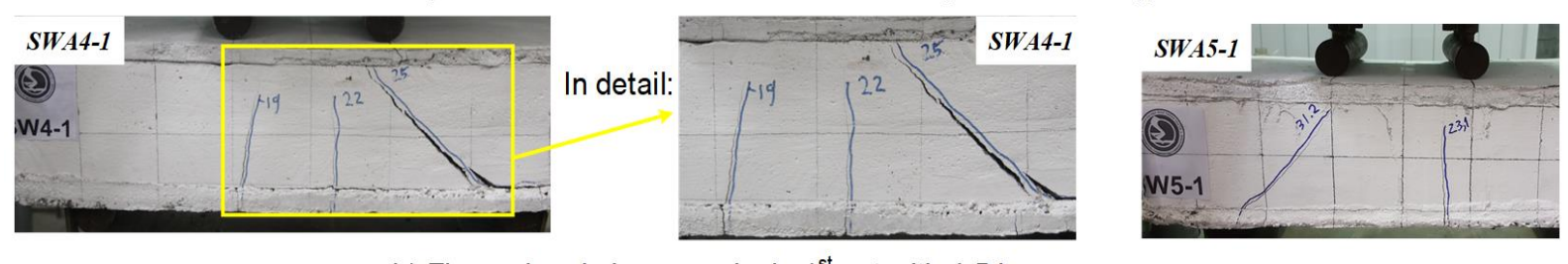

b) Flexural and shear cracks in $1^{\text {st }}$ set with 4,5 layers

Figure 7. Crack patterns of tested sandwich panels in $1^{\text {st }}$ set.

The behavior of all four panels in Set 2 specimens presented a typical shear failure mode, consisted of three stages namely: (a) the un-cracked stage, (b) the cracked stage and (c) the failure stage. The first visual diagonal cracks of the sandwich specimens form in the center of the load span. After cracking, the load still increased with the smaller stiffness, due to the dowel action of the longitudinal textile reinforcements. However, because of the distinct 
cellular structure in AAC core, the aggregate interlocking effect was not much actively, the panels failed gradually. As displayed in Figure 8 and Figure 9-b, the sandwich panels with 2 layers of glass textile type $\mathrm{C}$ in Set 3 had same shear failure manner to panels in Set 2.

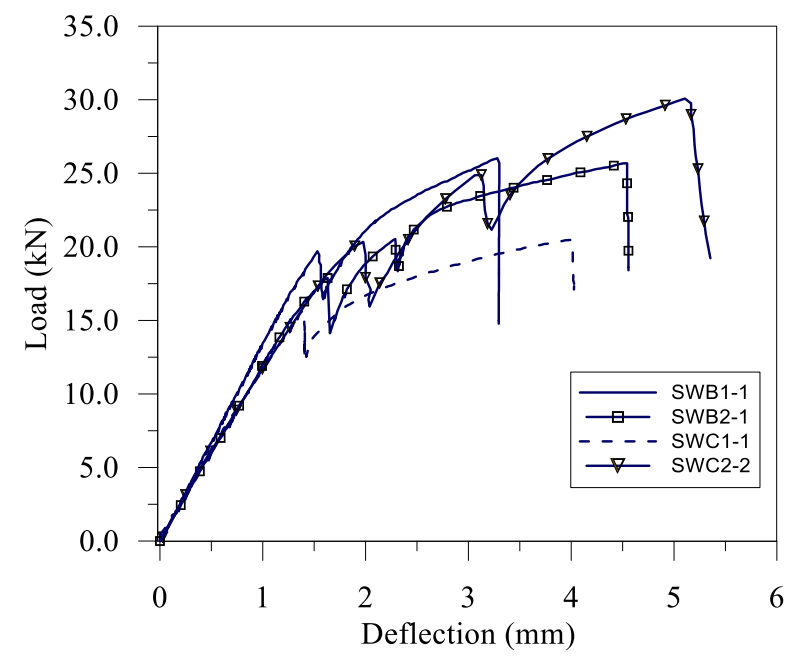

a) Sandwich beams in Set 2 and Set 3

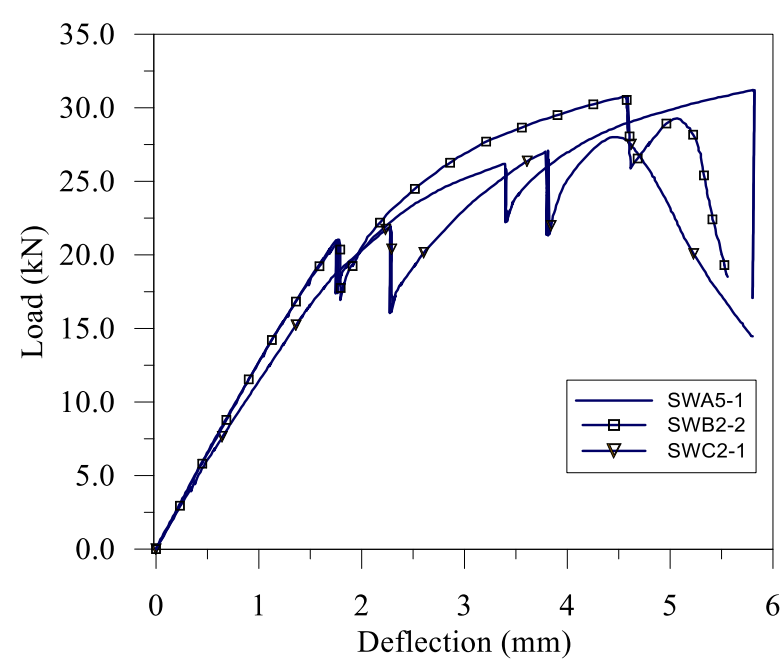

b) Compare sandwich beams in three sets

Figure 8. Crack patterns of sandwich panels in set 2 and 3.

On the other hand, two panels with 1 layer of textile in Set 3 had flexural failure. The load was linear up to the initiation of the first flexural crack in pure bending span, followed by a non-linear behavior up to failure. Since the glass textile has no plastic capacity, the sandwich panels failed when the reinforcement reach their tensile strength. All textile rovings were continuously broken in a brittle manner. Before breaking, there were no sign of compressive failure in top edge of sandwich panels.
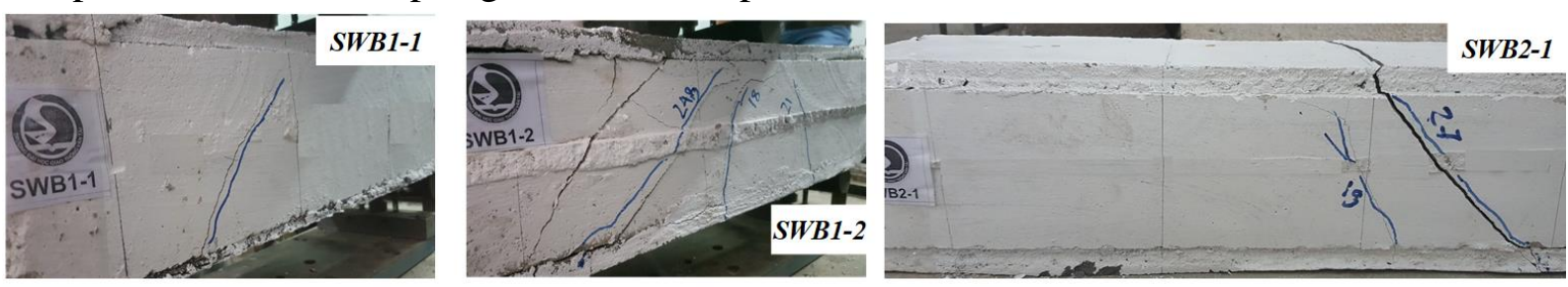

a) Shear failure of all beams in $2^{\text {nd }}$ set with glass textile type $B$

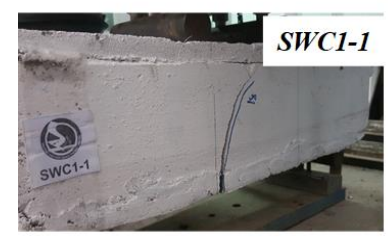

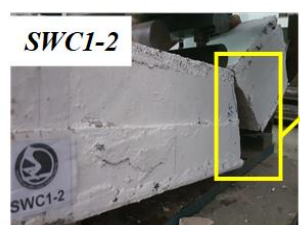

Flexural failure with 1 layer

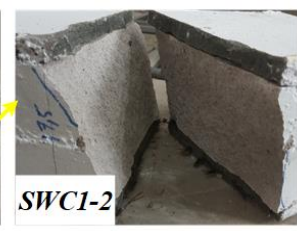

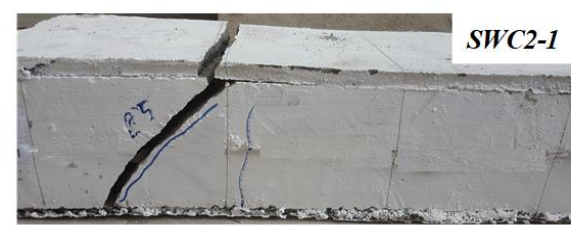

Shear failure with 2 layers

b) $3^{\text {rd }}$ set with glass textile type $C$

Figure 9. Crack patterns of sandwich panels in set 2 and 3.

\section{CONCLUSION}

This research proposed a new type of TRC-AAC sandwich panels. The main purpose of the study was to determine the flexural and shear performance of sandwich panels, with three different glass textile reinforcement types. The results show that, the adhesion performance was sufficient enough to safely transfer tensile loads from the TRC layer to the AAC core, 
Transport and Communications Science Journal, Vol. 71, Issue 1 (01/2020), 18-26

without any shear connector device. When the reinforcement ratios were small, the ultimate loads of the sandwich panels were reached when one of the vertical flexural cracks turned suddenly and developed widely through the AAC core. The failure of these occurred due to tensile break of textile reinforcements, along with the development of critical cracks. On the other hand, when the reinforcement ratios were large enough, the sandwich panels in three sets were failed in shear, with larger diagonal cracks.

\section{ACKNOWLEDGMENT}

This research is funded by University of Transport and Communications (UTC) under the project code T2019-KTXD-07TD. Authors would like to thank the Labaco-Building Co.ltd. for their support in AAC panel.

\section{REFERENCES}

[1] W. Brameshuber, Textile Reinforced Concrete. State-of-the Art, Report of RILEM Technical Comittee 201-TRC, 1st ed. Bagneux, vol. 36: RILEM Publications S.A.R.L., 2006.

[2] H. C. Nguyen, D.Q. Ngo, Flexural behavior of reinforced concrete beam strengthened by textile reinforced concrete: Experimental and numerical study, The Indian Concrete Journal, 92 (2018) 28-43.

[3] H. C. Nguyen, D.Q. Ngo, Numerical Analysis of Reinforced Concrete Beams Strengthened with Textile Reinforced Concrete, Proceedings of the International Conference on Engineering Mechanics and Automation-ICEMA3, Hanoi, Vietnam, October 15, 2014.

[4] J. Hegger, M. Horstmann, A. Scholzen, Sandwich panels with thin-walled textile-reinforced concrete facings, In American Concrete Institute (ACI) Special Publication, 2008. DOI: $10.14359 / 20153$

[5] H.N. Schneider et al., Modulare Bausystemeaus Textilbeton-sandwichelementen, 4th Colloquium on Textile Reinforced Structures, (2009) 565-576.

[6] V. A. Nguyen, A study on Textile Reinforced - and Expanded Polystyrene Concrete sandwich beams, PhD Dissertation, Technische Universität Dresden, 2016.

[7] V.H. Vu, D. Q. Ngo, T .T .T. Nguyen, H. C. Nguyen, Experimental analysis of sandwich panels using textile reinforced concrete faces and light weight concrete core, Science Journal of Transportation, Especial Issue No. 08, 2018.

[8] J. Radosław, D. Łukasz, Study of autoclaved aerated concrete masonry walls with horizontal reinforcement under compression and shear, Procedia Engineering, 161(2016) 918-924. https://doi.org/10.1016/j.proeng.2016.08.758

[9] M. Mousa, N. Uddin, Experimental and analytical study of carbon fiber-reinforced polymer (FRP)/autoclaved aerated concrete (AAC) sandwich panels, Journal of Engineering Structures, 31 (2009) 2337-2344. https://doi.org/10.1016/j.engstruct.2009.05.009

[10] N. Uddin, M.A. Mousa, U. Vaidya, F.H. Fouad, Book chapter: Design of hybrid fiber-reinforced polymer (FRP)/autoclave aerated concrete (AAC) panels for structural applications, In Woodhead Publishing Series in Civil and Structural Engineering, Developments in Fiber-Reinforced Polymer (FRP) Composites for Civil Engineering, Woodhead Publishing, 2013, 226-248. 